\title{
Examining the Properties of Neem Oil, Sunflower Oil and Mahua Oil with Antioxidants and Nano Powders for Power Transformer
}

\author{
Uma Devi Sankarasubbu, Senthil Kumar Suburaj* \\ Department of EEE, National Engineering Collge, Kovilpatti, India \\ Email address: \\ senthilkumarneceeegmail.com (S. K. Suburaj), malathiumadevi@gmail.com (U. D. Sankarasubbu) \\ ${ }^{*}$ Corresponding author
}

\section{To cite this article:}

Uma Devi Sankarasubbu, Senthil Kumar Suburaj. Examining the Properties of Neem Oil, Sunflower Oil and Mahua Oil with Antioxidants and Nano Powders for Power Transformer. American Journal of Electrical and Computer Engineering. Vol. 3, No. 1, 2019 , pp. $20-29$.

doi: 10.11648/j.ajece.20190301.13

Received: April 6, 2019; Accepted: May 14, 2019; Published: June 20, 2019

\begin{abstract}
In the newfangled world, electrical energy is the most important thing, and we cannot live without it. The recent research has predominated that petroleum by-products are available only for a few hundred years. This paper is especially clear to meet out that. After some years, the mineral oil in the transformer needs to be changed due to its degradation of insulation. The mineral oil used in the transformer acts as insulation as well as cooling purpose. The used mineral oil can be recycled by adding some additives for reuse purpose. In this paper, the oil chosen is neem oil, sunflower oil and mahua oil and it is treated with antioxidants and nano powders. "Breakdown voltage, flash point, fire point, acidity, and viscosity are measured in consonance with standards". To reduce the oxidation stability natural and synthetic antioxidants are preferred, and Nano powders are also used for improving the properties of the oil. Synthetic antioxidants such as Beta Carotene and TBHQ and selenium are preferred as natural antioxidants. Selenium is used. Before and after the addition of antioxidants and nano powders the measurements were done. By doing this analysis, the transformer oil is used for reuse purpose and it has a longer lifetime. After antioxidants and Nano powders are added, the property of the transformer oil is increased.
\end{abstract}

Keywords: Nano Powders, Antioxidants, Break Down Voltage, Flash Point, Fire Point, Viscosity, Acidity

\section{Introduction}

\subsection{Background}

Transformer oil is used for insulation purpose. It is obtained by petroleum by-products and so it is named as mineral insulating oil. Transformer oil serves mainly two purposes one it is liquid insulation in electrical power transformer and two it dissipates heat of the transformer that is it acts as a coolant. It also helps in another two reasons, one to preserve the core and winding as these are fully immersed inside oil, and next preventing the direct contact of atmospheric oxygen [1].

In the transformer there are two types of transformer oil are used. They are

i. Paraffin-based transformer oil

ii. Naphtha-based transformer oil
Naphtha oil gets more easily oxidized than Paraffin oil. Sludge formation present in the naphtha oil is more when compared to paraffin oil [2]. Thus sludge is not formed in the bottom of the transformer and does not disturb the cooling system of the transformer. But in the case of Paraffin oil although the oxidation rate is lower. Although Paraffin-based oil has a disadvantage because we use it because of its easy availability. High pour point problem is found in paraffinic oil due to the wax content, but this does not affect its use due to warm climate condition of India [3-5].

\subsection{Compound Description}

\subsubsection{Antioxidants}

An Antioxidant is the chemical compounds which can delay the start or slow the rate of lipid oxidation reaction in food systems both natural and synthetic antioxidants are used in the food industry as food additives. Oxidative 
degeneration is stated to have been caused by harmful molecules called free radicals. Free radicals are molecular fragments having one (or) more unpaired electrons [6-8].

\subsubsection{Nanopowders}

Nanopowders are defined as powdered materials with individual particles having sizes fewer than 100 nanometers. The particles present in the nanopowders are very smaller when compared with the wavelength of visible light $[9,10]$. The smaller size of nanopowders gives them an extremely high surface area to volume ratio that results in extraordinary properties like extreme strength. Below formula is used to calculate the number of nanoparticles to be added with the oil for preparation of nanofluids:

$$
\text { Weight of the nanoparticles }=(\text { density } * \text { Volume }) / \text { (Volume Fraction })
$$

The above euation A represents the equation for calculating the nano power weight added to the oil samples.

\section{Methodology}

The methodology includes standards, measurements, sample description and sample preparation. Sample description and sample preparation are done for neem oil, sunflower oil and mahua oil.

\subsection{Standards}

The measurement of oil properties like Viscosity, Breakdown Voltage, Acidity, Flash and Fire pointis carried out according to IEC and ASTM standards [11-13]. The method standard used and standard values are given in Table 1.

Table 1. Standards and Methodology for Measurement.

\begin{tabular}{lll}
\hline Parameters & Method/Equipment & Standard \\
\hline Breakdown Voltage & Breakdown Voltage Kit & IEC 60156 \\
Viscosity & Redwood Viscometer & ASTM D-445 \\
Flash Point and Fire Point & Pensky Martin Closed Cup Method & ASTM D-93 \\
Acidity & Color Chart & - \\
\hline
\end{tabular}

\subsection{Measurement of Breakdown Voltage}

The dielectric strength of transformer oil is also known as the Breakdown voltage of transformer oil. The low value of BDV indicates the presence of moisture content and conducting substance in the oil. In BDV kit, oil is kept in a pot in which one pair of the electrode is fixed with a gap of $2.5 \mathrm{~mm}$ between them [14]. By raising the voltage measurement is taken 3 to 5 times in the same sample of oil. The breakdown Voltage testing kit is shown in Figure 1.

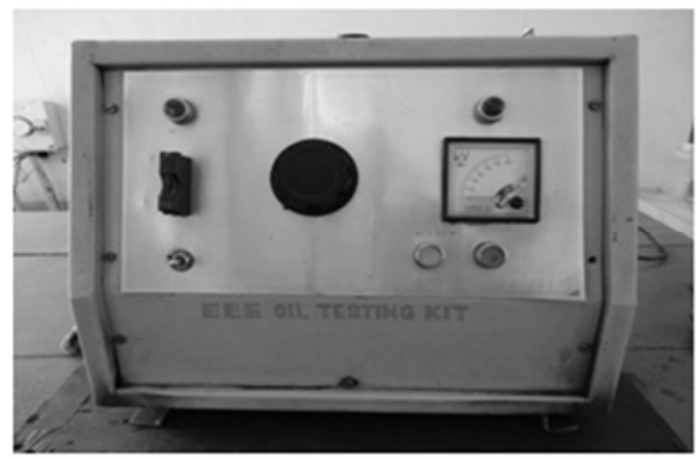

Figure 1. BDV Test Kit.

\subsection{Measurement of Viscosity}

Technically the viscosity of the oil is a measure of the oil resistance to shear. Viscosity is more commonly known as resistance flow. The measurement of viscosity the resistance to flow between the individual layers [15]. A high viscosity implies high resistance to flow while a low viscosity indicates a low resistance to flow. Viscosity varies inversely with temperature [21]. The Redwood viscometer is shown in Figure 2.

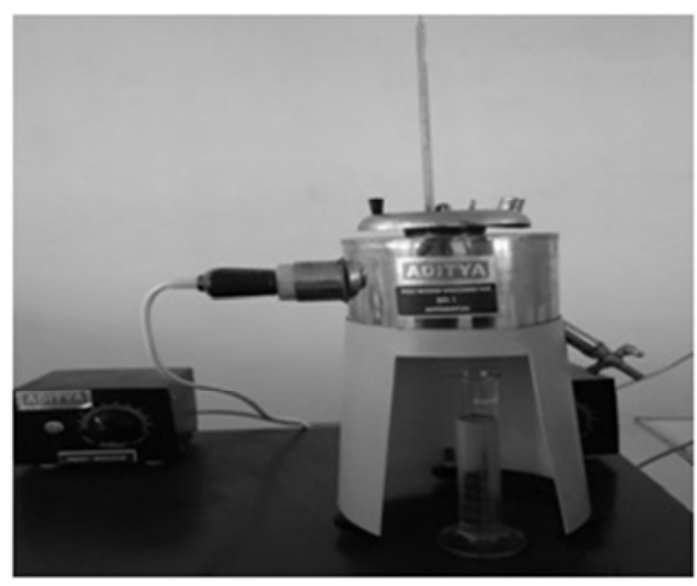

Figure 2. Redwood Viscometer.

\subsection{Measurement of Flash and Fire Point}

Flashpoint of a volatile liquid is the lowest temperature at which it can vaporize to form an ignitable mixture in air. Measuring a liquid's flashpoint requires an ignition source [16]. The flash point is often used as one descriptive characteristic of liquid fuel, but it also used to describe liquids that are not used intentionally as fuels [22].

The temperature at which the vapor continues to burn after being ignited is called fire point. It is the lowest temperature at which, on further heating beyond the flash point the sample will support combustion for 5 seconds. The Pensky Martins Closed Cup apparatus is shown in Figure 3. 


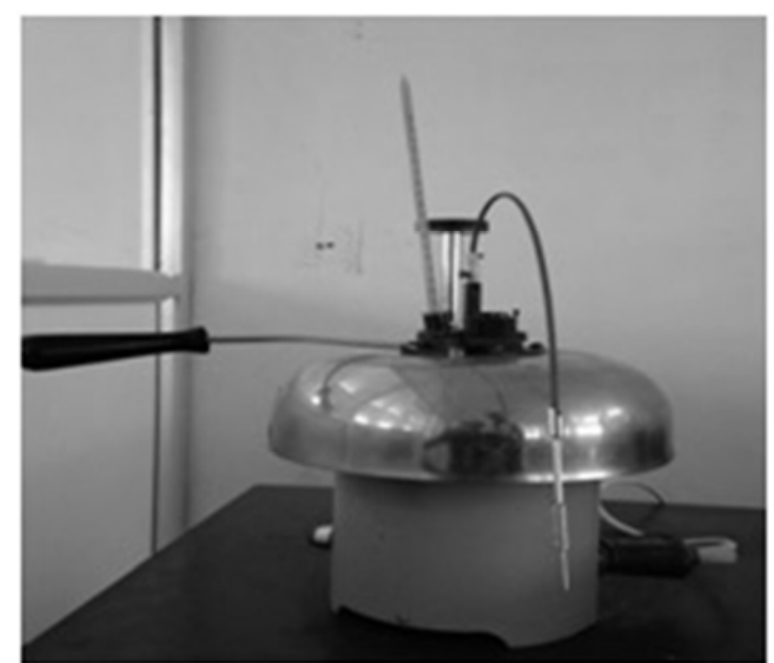

Figure 3. Pensky Martin Closed Cup Apparatus.

\subsection{Measurement of Acidity}

The acidity is calculated by using colour chart method. The colour code for determining the acidity is shown in figure $4.1 .1 \mathrm{mlof}$ the oil sample and $1 \mathrm{ml}$ of ethyl alcohol are mixed and after shaking well $1 \mathrm{ml}$ of sodium carbonate is added [17]. After re shaking well 5 drops of universal indicator solution is added and mixed well. By using the colour chart acid content in oil sample is found in $\mathrm{KoH} / \mathrm{g}$.

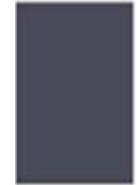

0.00

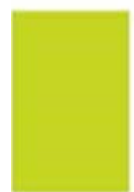

0.4

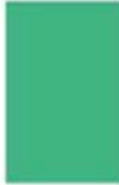

0.05

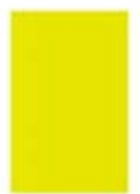

0.5

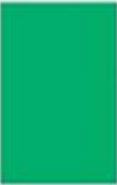

0.1

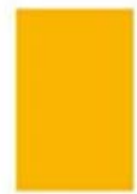

0.6

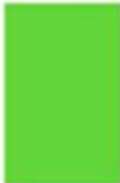

0.2

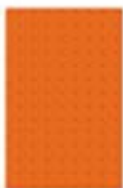

0.7

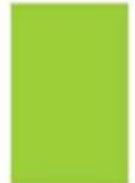

0.3

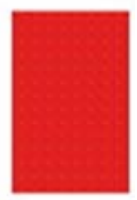

0.8
Figure 4. Acidity Test color chart.

\subsection{Sample Description}

The vegetable oil is mixed in different proportions like neem oil, sunflower oil and mahua oil with different antioxidants and nanopowders [18-20]. Samples prepared using neem oil with antioxidants and nanopowders are shown in Table 2.

Table 2. Sample Combination Using Neem Oil.

\begin{tabular}{ll}
\hline Samples & Sample Name \\
\hline Sample 1 & $500 \mathrm{ml}$ of neem oil \\
Sample 2 & $500 \mathrm{ml}$ of neem oil $+1 \mathrm{~g}$ TBHQ \\
Sample 3 & $500 \mathrm{ml}$ of neem oil $+1 \mathrm{~g}$ Selenium \\
Sample 4 & $500 \mathrm{ml}$ of neem oil $+1 \mathrm{~g}$ Beta Carotene \\
Sample 5 & $500 \mathrm{ml}$ of neem oil $+0.5 \mathrm{~g}$ Selenium $+0.5 \mathrm{~g}$ Beta Carotene \\
Sample 6 & $500 \mathrm{ml}$ of neem oil0.5g Selenium $+0.5 \mathrm{~g}$ TBHQ \\
Sample 7 & $500 \mathrm{ml}$ of neem oil0.5g TBHQ $+0.5 \mathrm{~g}$ Beta Carotene \\
Sample 8 & $500 \mathrm{ml}$ of neem oil0.3g Selenium $+0.3 \mathrm{~g}$ Beta Carotene $+0.3 \mathrm{~g}$ TBHQ \\
Sample 9 & $500 \mathrm{ml}$ of neem oil $+2.5 \mathrm{~g}$ Aluminium Nitride \\
Sample 10 & $500 \mathrm{ml}$ of neem oil $+1.06 \mathrm{~g}$ Carbon Nano Powder \\
Sample 11 & $500 \mathrm{ml}$ of neem oil $+0.96 \mathrm{~g}$ Carbon Nano Powder $+0.96 \mathrm{~g}$ Aluminium Nitride \\
\hline
\end{tabular}

Samples prepared using sunflower oil with antioxidants and nanopowders are shown in Table 3.

Table 3. Sample Combination Using Sunflower Oil.

\begin{tabular}{ll}
\hline Samples & Sample Name \\
\hline Sample 1 & $500 \mathrm{ml}$ of sunflower oil \\
Sample 2 & $500 \mathrm{ml}$ of sunflower oil $+1 \mathrm{~g}$ TBHQ \\
Sample 3 & $500 \mathrm{ml}$ of sunflower oil $+1 \mathrm{~g}$ Selenium \\
Sample 4 & $500 \mathrm{ml}$ of sunflower oil $+1 \mathrm{~g}$ Beta Carotene \\
Sample 5 & $500 \mathrm{ml}$ of sunflower oil $+0.5 \mathrm{~g}$ Selenium $+0.5 \mathrm{~g}$ Beta Carotene \\
Sample 6 & $500 \mathrm{ml}$ of sunflower oil0.5g Selenium $+0.5 \mathrm{~g}$ TBHQ \\
Sample 7 & $500 \mathrm{ml}$ of sunflower oil0.5g TBHQ $+0.5 \mathrm{~g}$ Beta Carotene \\
Sample 8 & $500 \mathrm{ml}$ of sunflower oil0.3g Selenium $+0.3 \mathrm{~g}$ Beta Carotene $+0.3 \mathrm{~g}$ TBHQ \\
Sample 9 & $500 \mathrm{ml}$ of sunflower oil $+2.5 \mathrm{~g}$ Aluminium Nitride \\
Sample 10 & $500 \mathrm{ml}$ of sunflower oil $+1.06 \mathrm{~g}$ Carbon Nano Powder \\
Sample 11 & $500 \mathrm{ml}$ of sunflower oil $+0.96 \mathrm{~g}$ Carbon Nano Powder $+0.96 \mathrm{~g}$ Aluminium Nitride \\
\hline
\end{tabular}

Samples prepared using mahua oil with antioxidants and nanopowders are shown in Table 4. 
Table 4. Sample Combination Using Mahua Oil.

\begin{tabular}{ll}
\hline Samples & Sample Name \\
\hline Sample 1 & $500 \mathrm{ml}$ of mahua oil \\
Sample 2 & $500 \mathrm{ml}$ of mahua oil $+1 \mathrm{~g}$ TBHQ \\
Sample 3 & $500 \mathrm{ml}$ of mahua oil $+1 \mathrm{~g}$ Selenium \\
Sample 4 & $500 \mathrm{ml}$ of mahua oil $+1 \mathrm{~g}$ Beta Carotene \\
Sample 5 & $500 \mathrm{ml}$ of mahua oil $+0.5 \mathrm{~g}$ Selenium $+0.5 \mathrm{~g}$ Beta Carotene \\
Sample 6 & $500 \mathrm{ml}$ of mahua oil0.5g Selenium $+0.5 \mathrm{~g}$ TBHQ \\
Sample 7 & $500 \mathrm{ml}$ of mahua oil0.5g TBHQ $+0.5 \mathrm{~g}$ Beta Carotene \\
Sample 8 & $500 \mathrm{ml}$ of mahua oil0.3g Selenium $+0.3 \mathrm{~g}$ Beta Carotene $+0.3 \mathrm{~g}$ TBHQ \\
Sample 9 & $500 \mathrm{ml}$ of mahua oil $+2.5 \mathrm{~g}$ Aluminium Nitride \\
Sample 10 & $500 \mathrm{ml}$ of mahua oil $+1.06 \mathrm{~g}$ Carbon Nano Powder \\
Sample 11 & of mahua oil $+0.96 \mathrm{~g}$ Carbon Nano Powder $+0.96 \mathrm{~g}$ Aluminium Nitride \\
\hline
\end{tabular}

\subsection{Sample Preparation}

The neem oil, sunflower oil and mahua oil of $500 \mathrm{ml}$ is mixed with the single and combination antioxidants like TBHQ, selenium and beta carotene and nanopowders like aluminium nitride and carbon nanopowder and mixed using magnetic stirrer unit for 20 to 30 minutes under 750 RPM.

\section{Result and Discussion}

The results are obtained from the combination of neem oil, sunflower oil and mahua oil blended with regenerative materials. The critical parameters of the samples are improved by using this.

\subsection{The Blending of Neem Oil with Regenerative Materials}

The results are obtained from the experiment are presented here in Table 5. The evaluation of critical parameters of Neem Oil by way of different proportions through the addition of regenerative materials like TBHQ, Selenium, Beta Carotene, Aluminium Nitride and Carbon Nanopowder were made.

Table 5. Results of Neem oil with Regenerative Materials.

\begin{tabular}{|c|c|c|c|c|c|c|}
\hline Samples & BDV(kV) & Viscosity at $40^{\circ} \mathrm{C}(\mathrm{cSt})$ & Viscosity at $90^{\circ} \mathrm{C}(\mathrm{cSt})$ & Flash Point $\left({ }^{\circ} \mathrm{C}\right)$ & Fire Point $\left({ }^{\circ} \mathrm{C}\right)$ & Acidity (KoH/g) \\
\hline Sample 1 & 20 & 145.8 & 41.05 & 230 & 250 & 0.6 \\
\hline Sample 2 & 22.1 & 113.2 & 34.10 & 260 & 283 & 0.1 \\
\hline Sample 3 & 23.8 & 94.95 & 34.10 & 238 & 257 & 0.1 \\
\hline Sample 4 & 22.3 & 110.1 & 34.90 & 243 & 259 & 0.4 \\
\hline Sample 5 & 27.8 & 82.40 & 28.40 & 218 & 238 & 0.6 \\
\hline Sample 6 & 25.1 & 48.50 & 14.52 & 232 & 248 & 0.3 \\
\hline Sample 7 & 21.5 & 87.11 & 28.40 & 243 & 261 & 0.4 \\
\hline Sample 9 & 26.3 & 86.3 & 28.13 & 283 & 313 & 0.4 \\
\hline Sample 10 & 29 & 97.04 & 26.49 & 279 & 296 & 0.05 \\
\hline Sample 11 & 26.2 & 74.81 & 24.28 & 273 & 295 & 0.1 \\
\hline
\end{tabular}

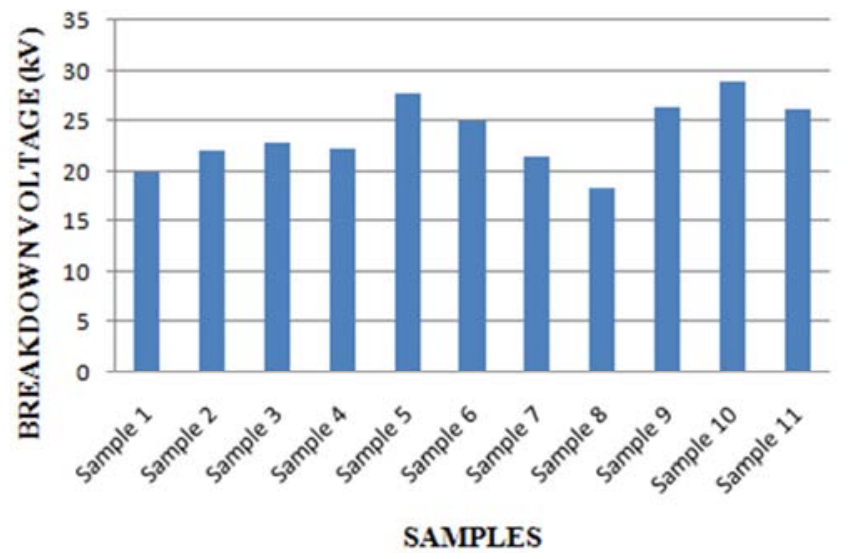

Figure 5. Comparison of Breakdown Voltage values of samples using neem oil.

Figure 5 shows the comparison graph of breakdown voltage for different samples using neem oil.

From the Investigations of the breakdown Voltage of the neem oil sample the following inference were made:
1. Breakdown Voltage of the neemoil sample increases when Antioxidants and nano powders are added.

2. When Carbon nano powder is added the breakdown Voltage (Sample 10) is higher when compared with other.

3. The breakdown voltage is increased from $18.4 \mathrm{kV}$ to $29 \mathrm{kV}$.

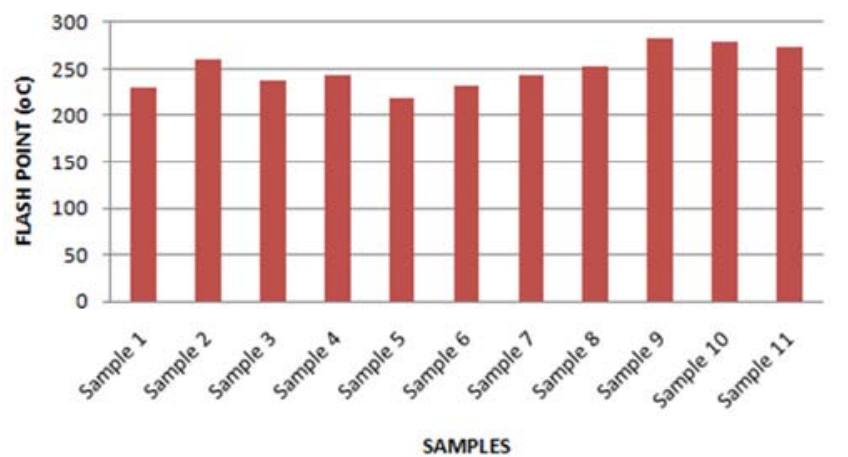

Figure 6. Comparison of Flash point values of samples using neem oil. 
Figure 6 shows the comparison graph of Flash point for different samples using neem oil.

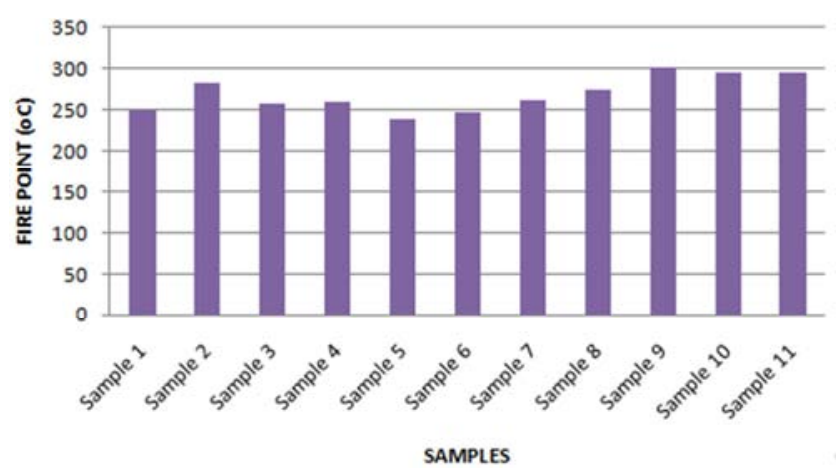

Figure 7. Acidity Comparison of Fire point values of samples using neem oil.

Figure 7 shows the comparison graph of Fire point for different samples using neem oil.

From the Investigations of the Flash Point and Fire Point of the neem oil sample the following inference were made:

1. The flash point is increased from $218^{\circ} \mathrm{C}$ to $283^{\circ} \mathrm{C}$.

2. The fire point is the withstand temperature of the oil sample.

3. The flash point and Fire point for Sample 10 that is when carbon nano powder is very high.

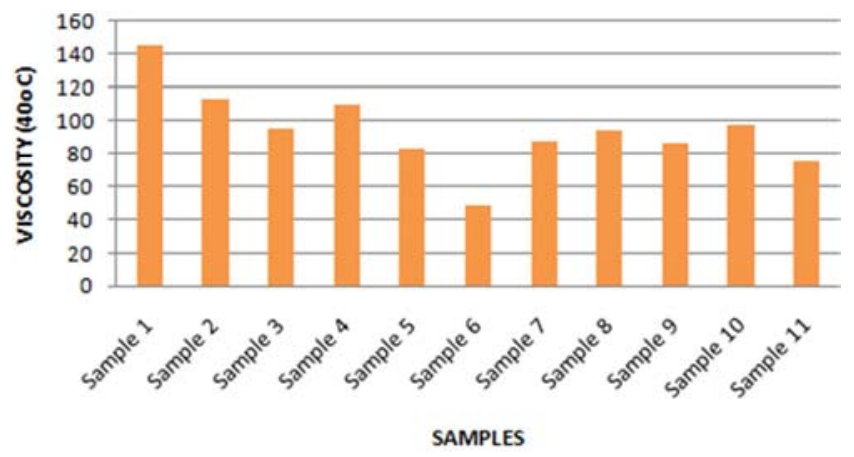

Figure 8. Comparison of Viscosity values of samples using neem oil at $40^{\circ} \mathrm{C}$.

Figure 8 shows the comparison graph of Viscosities for different samples using neem oil at $40^{\circ} \mathrm{C}$.

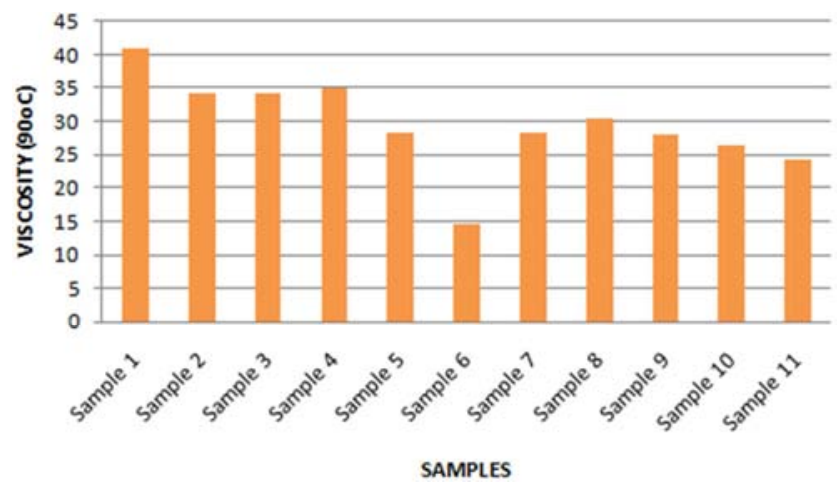

Figure 9. Comparison of Viscosity values of samples using neem oil at $90^{\circ} \mathrm{C}$.

Figure 9 shows the comparison graph of Viscosities for different samples using neem oil at $90^{\circ} \mathrm{C}$.
From the Investigations of the Viscosity values of the neem oil sample the following inference were made:

1. At $40^{\circ} \mathrm{C}$, the viscosity of the oil sample gets reduced from $145.81 \mathrm{cSt}$ to $48.50 \mathrm{cSt}$.

2. At $90^{\circ} \mathrm{C}$, the viscosity of the oil sample gets reduced from $41.05 \mathrm{cSt}$ to $14.52 \mathrm{cSt}$.

3. The viscosity values of sample 6 that is when neemoil is mixed with selenium and TBHQ is very low.

4. Usually lower the viscosity value gives the better oil sample.

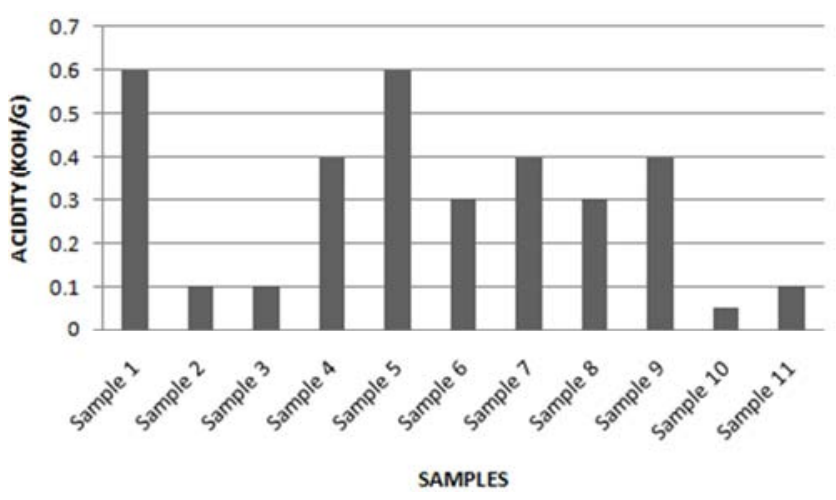

Figure 10. Comparison of Acidity values of samples using neem oil.

Figure 10 shows the comparison graph of Acidity for different samples using neem oil.

From the Investigations of the Acidity values of the neem oil sample the following inference were made:

1. The acidity of the oil sample gets reduced from $0.6 \mathrm{KoH} / \mathrm{g}$ to $0.05 \mathrm{KoH} / \mathrm{g}$.

2. The acidity value for Sample 10 that is when carbon nano powder is low.

\subsection{The Blending of Sunflower Oil with Regenerative Materials}

The results are obtained from the experiment are presented here in Table 6. The evaluation of critical parameters of Neem Oil by way of different proportions through the addition of regenerative materials like TBHQ, Selenium, Beta Carotene, Aluminium Nitride and Carbon Nanopowder were made.

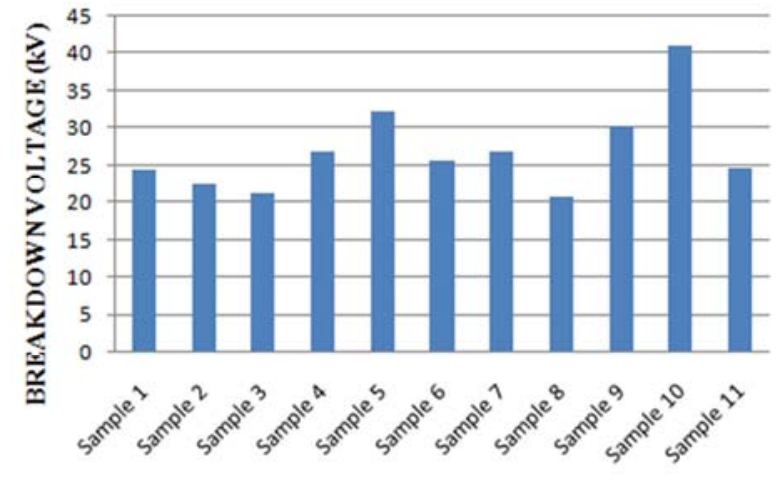

SAMPLES

Figure 11. Comparison of Breakdown Voltage values of samples using sunflower oil. 
Table 6. Results of Sunflower oil with Regenerative Materials.

\begin{tabular}{lllllll}
\hline Samples & BDV $(\mathbf{k V})$ & Viscosity at $\mathbf{4 0} \mathbf{~}^{\mathbf{C}} \mathbf{C}(\mathbf{c S t})$ & Viscosity at $\mathbf{9 0} \mathbf{0}^{\circ} \mathbf{C}(\mathbf{c S t})$ & Flash Point $\left({ }^{\circ} \mathbf{C}\right)$ & Fire Point $\left({ }^{\circ} \mathbf{C}\right)$ & Acidity $(\mathbf{K o H} / \mathbf{g})$ \\
\hline Sample 1 & 24.5 & 42.66 & 26.21 & 311 & 331 & 0.05 \\
Sample 2 & 22.4 & 115.3 & 52.46 & 321 & 346 & 0.05 \\
Sample 3 & 21.3 & 90.51 & 25.66 & 316 & 331 & 0.1 \\
Sample 4 & 26.9 & 75.85 & 26.21 & 306 & 324 & 0 \\
Sample 5 & 32.4 & 84.49 & 30.04 & 317 & 330 & 0 \\
Sample 6 & 25.6 & 90.25 & 26.21 & 329 & 352 & 0.05 \\
Sample 7 & 27 & 48.50 & 23.72 & 324 & 347 & 0.7 \\
Sample 8 & 20.9 & 90.51 & 55.1 & 339 & 362 & 0.4 \\
Sample 9 & 30.3 & 70.87 & 25.94 & 335 & 357 & 0.1 \\
Sample 10 & 41 & 66.15 & 20.93 & 346 & 364 & 0.05 \\
Sample 11 & 24.8 & 91.55 & 23.17 & 336 & 353 & 0 \\
\hline
\end{tabular}

Figure 11 shows the comparison graph of breakdown voltage for different samples using sunflower oil.

From the Investigations of the breakdown Voltage of the sunflower oil sample the following inference were made:

1. Breakdown Voltage of the sunflower oil sample increases when Antioxidants and nano powders are added.

2. When Carbon nano powder is added the Breakdown Voltage (Sample 10) is higher when compared with other.

3. The breakdown voltage is increased from $21.3 \mathrm{kV}$ to $41 \mathrm{kV}$.

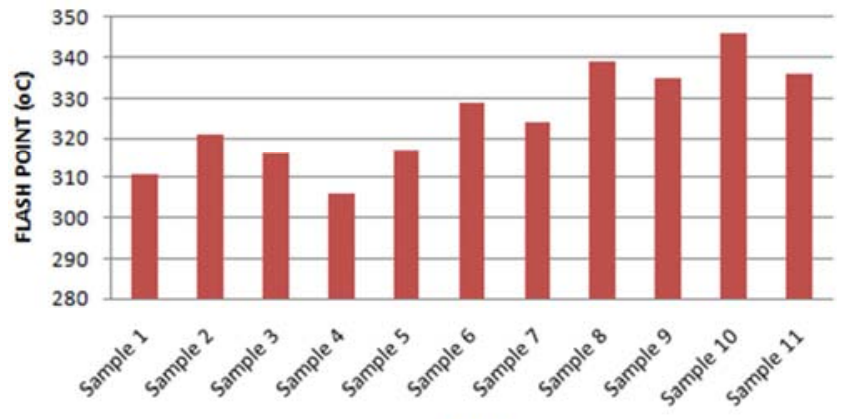

SAMPLES

Figure 12. Comparison of Flash point values of samples using sunflower oil.

Figure 12 shows the comparison graph of Flash point for different samples using sunflower oil.

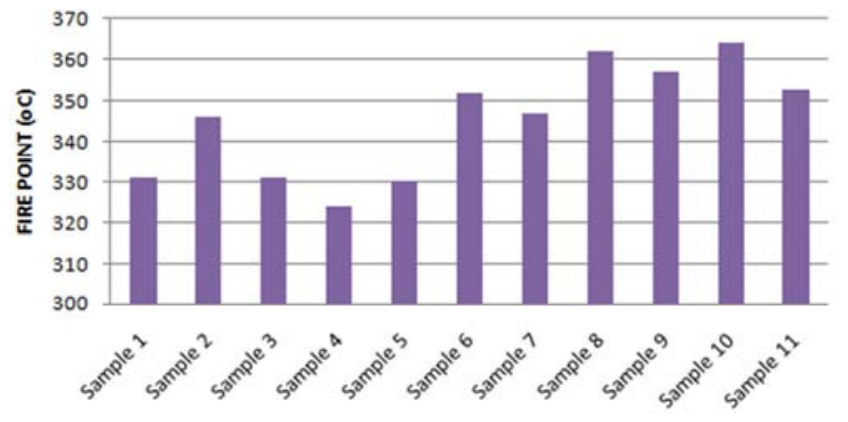

SAMPLES

Figure 13. Acidity Comparison of Fire point values of samples using sunflower oil.

Figure 13 shows the comparison graph of Fire point for different samples using sunflower oil.
From the Investigations of the Flash Point and Fire Point of the sunflower oil sample the following inference were made:

1. The flash point is increased from $306^{\circ} \mathrm{C}$ to $346^{\circ} \mathrm{C}$.

2. The fire point is the withstand temperature of the oil sample.

3. The flash point and Fire point for Sample 10 that is when carbon nano powder is very high.

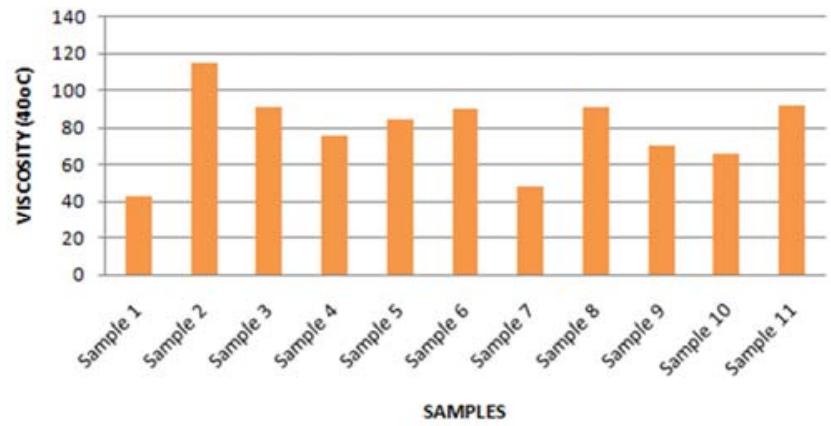

Figure 14. Comparison of Viscosity values of samples using sunflower oil at $40^{\circ} \mathrm{C}$

Figure 14 Comparison of Viscosity values of samples using sunflower oil at $40^{\circ} \mathrm{C}$.

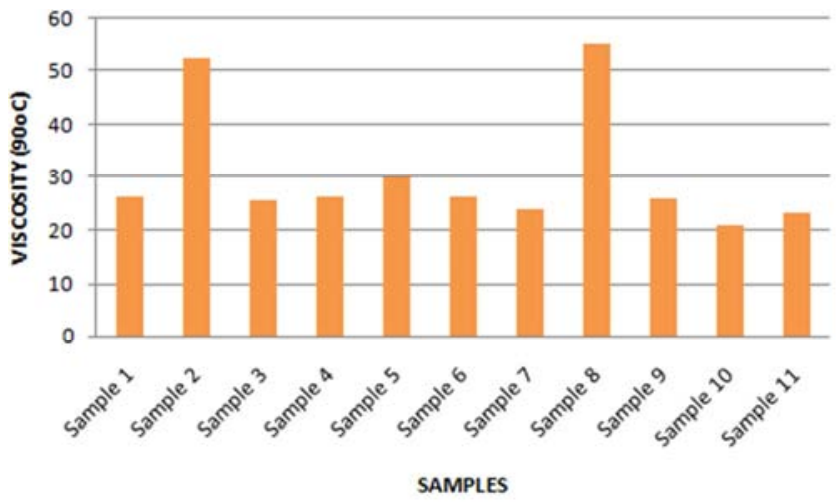

Figure 15. Comparison of Viscosity values of samples using sunflower oil at $90^{\circ} \mathrm{C}$.

Figure 15 shows the comparison graph of Viscosities for different samples using sunflower oil at $90^{\circ} \mathrm{C}$.

From the Investigations of the Viscosity values of the sunflower oil sample the following inference were made: 
1. At $40^{\circ} \mathrm{C}$, the viscosity of the oil sample gets reduced from $115.31 \mathrm{cSt}$ to $42.66 \mathrm{cSt}$.

2. At $90^{\circ} \mathrm{C}$, the viscosity of the oil sample gets reduced from $55.1 \mathrm{cSt}$ to $20.93 \mathrm{cSt}$.

3. The viscosity values of sample 10 that is when mahua oil is mixed with selenium and TBHQ is very low.

4. Usually lower the viscosity value gives the better oil sample.

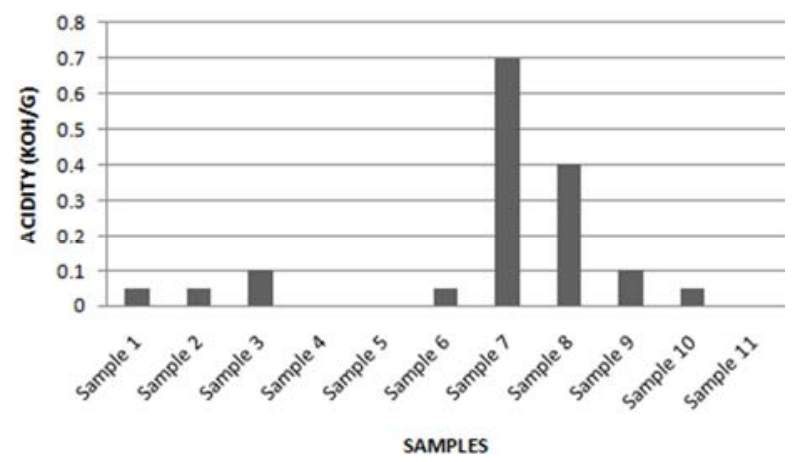

Figure 16. Comparison of Acidity values of samples using sunflower oil.
Figure 16 shows the comparison graph of Acidity for different samples using sunflower oil.

From the Investigations of the Acidity values of the sunflower oil sample the following inference were made:

1. The acidity of the oil sample gets reduced from $0.7 \mathrm{KoH} / \mathrm{g}$ to $0 \mathrm{KoH} / \mathrm{g}$.

2. The acidity value for Sample 4, 5 and 11 that is when beta carotene, selenium and beta carotene andwhen carbon and aluminium nano powder is added is low.

\subsection{The Blending of MahuaOil with Regenerative Materials}

The results are obtained from the experiment are presented here in Table 7. The evaluation of critical parameters of Neem Oil by way of different proportions through the addition of regenerative materials like TBHQ, Selenium, Beta Carotene, Aluminium Nitride and Carbon Nanopowder were made.

Table 7. Results of Mahua oil with Regenerative Materials.

\begin{tabular}{|c|c|c|c|c|c|c|}
\hline Samples & BDV (kV) & Viscosity at $40^{\circ} \mathrm{C}(\mathrm{cSt})$ & Viscosity at $90^{\circ} \mathrm{C}(\mathrm{cSt})$ & Flash Point $\left({ }^{\circ} \mathrm{C}\right)$ & Fire Point $\left({ }^{\circ} \mathrm{C}\right)$ & Acidity (KoH/g) \\
\hline Sample 1 & 24.9 & 298.5 & 30.85 & 270 & 290 & 0.1 \\
\hline Sample 2 & 15.4 & 80.83 & 30.58 & 240 & 260 & 0.4 \\
\hline Sample 3 & 23.1 & 81.88 & 37.85 & 250 & 268 & 0.05 \\
\hline Sample 4 & 26.6 & 96.52 & 27.04 & 258 & 273 & 0.6 \\
\hline Sample 5 & 18.6 & 115.0 & 28.13 & 252 & 269 & 0.4 \\
\hline Sample 6 & 16.9 & 103.5 & 30.04 & 280 & 298 & 0.3 \\
\hline Sample 8 & 28.6 & 123.3 & 31.39 & 310 & 325 & 0.1 \\
\hline Sample 9 & 29.4 & 109.3 & 46.37 & 290 & 313 & 0.05 \\
\hline Sample 10 & 27.9 & 108.2 & 22.89 & 268 & 291 & 0.1 \\
\hline Sample 11 & 25.3 & 183.2 & 56.42 & 285 & 309 & 0.2 \\
\hline
\end{tabular}

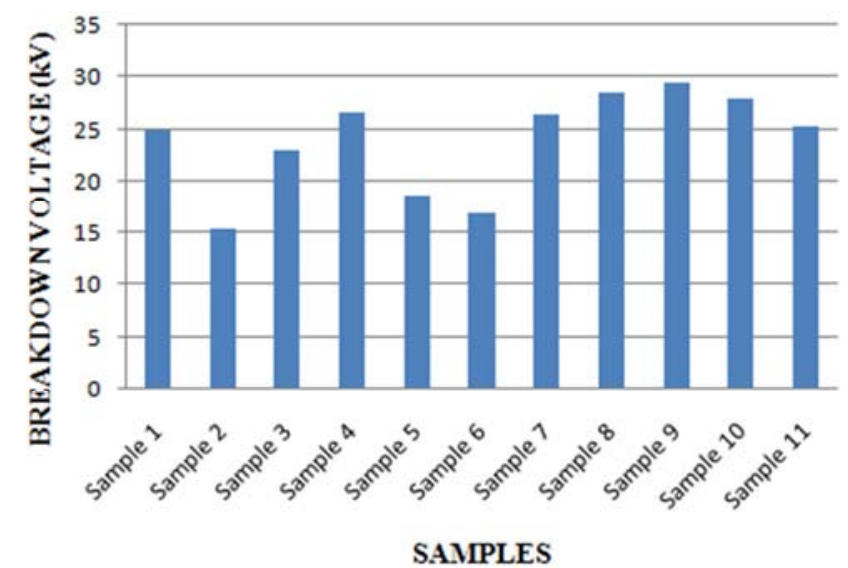

Figure 17. Comparison of Breakdown Voltage values of samples using mahua oil.

Figure 17 shows the comparison graph of breakdown voltage for different samples using mahua oil.

From the Investigations of the breakdown Voltage of the mahua oil sample the following inference were made:
1. Breakdown Voltage of the mahua oil sample increases when Antioxidants and nano powders are added.

2. When Aluminium Nitride nano powder is added the Breakdown Voltage (Sample 9) is higher when compared with other.

3. The breakdown voltage is increased from $15.4 \mathrm{kV}$ to $29.4 \mathrm{kV}$.

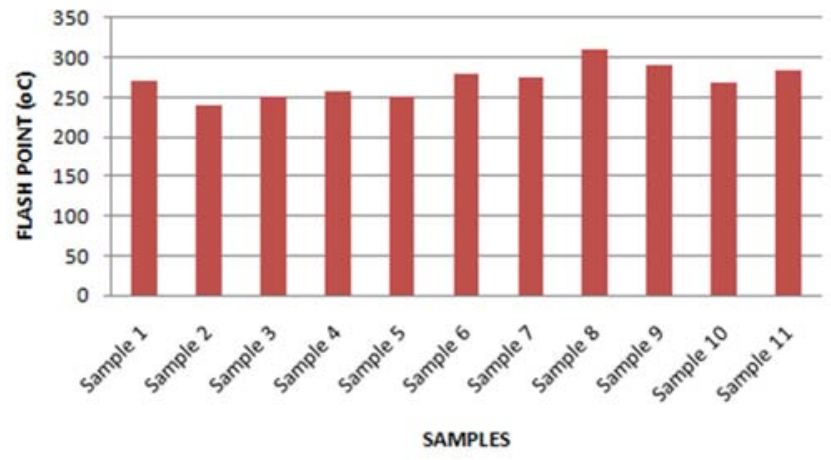

Figure 18. Comparison of Flash point values of samples using mahua oil.

Figure 18 shows the comparison graph of Flash point for 
different samples using mahua oil.

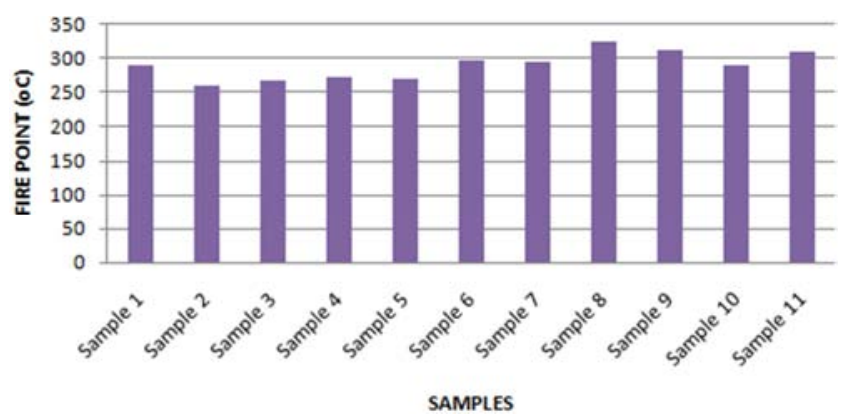

Figure 19. Acidity Comparison of Fire point values of samples using mahua oil.

Figure 19 shows the comparison graph of Fire point for different samples using mahua oil.

1. From the Investigations of the Flash Point and Fire Point of the mahua oil sample the following inference were made:

2. The flash point is increased from $240^{\circ} \mathrm{C}$ to $310^{\circ} \mathrm{C}$.

3. The fire point is the withstand temperature of the oil sample.

4. The flash point and Fire point for Sample 8 that is when carbon nano powder is very high.

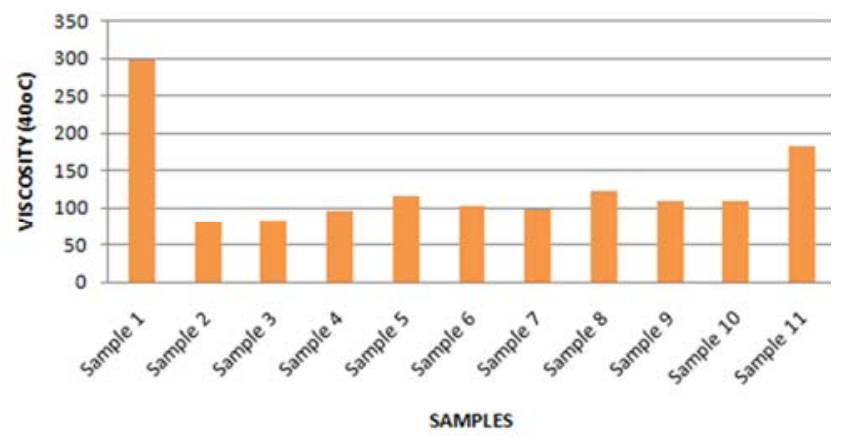

Figure 20. Comparison of Viscosity values of samples using mahua oil at $40^{\circ} \mathrm{C}$.

Figure 20 shows the comparison graph of Viscosities for different samples using mahua oil at $40^{\circ} \mathrm{C}$.

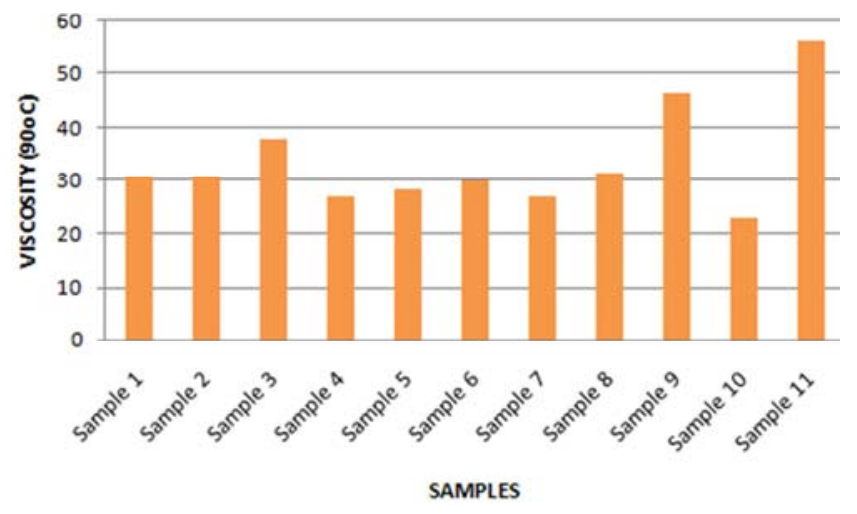

Figure 21. Comparison of Viscosity values of samples using mahua oil at $90^{\circ} \mathrm{C}$

Figure 21 shows the comparison graph of Viscosities for different samples using mahua oil at $90^{\circ} \mathrm{C}$.

From the Investigations of the Viscosity values of the sunflower oil sample the following inference were made:

1. At $40^{\circ} \mathrm{C}$, the viscosity of the oil sample gets reduced from $298.53 .81 \mathrm{cSt}$ to $80.83 \mathrm{cSt}$.

2. At $90^{\circ} \mathrm{C}$, The viscosity of the oil sample gets reduced from $56.42 \mathrm{cSt}$ to $22.89 \mathrm{cSt}$.

3 . The viscosity value of sample 10 that is when mahua oil is mixed with Carbon nano powder is very low.

4. Usually lower the viscosity value gives the better oil sample.

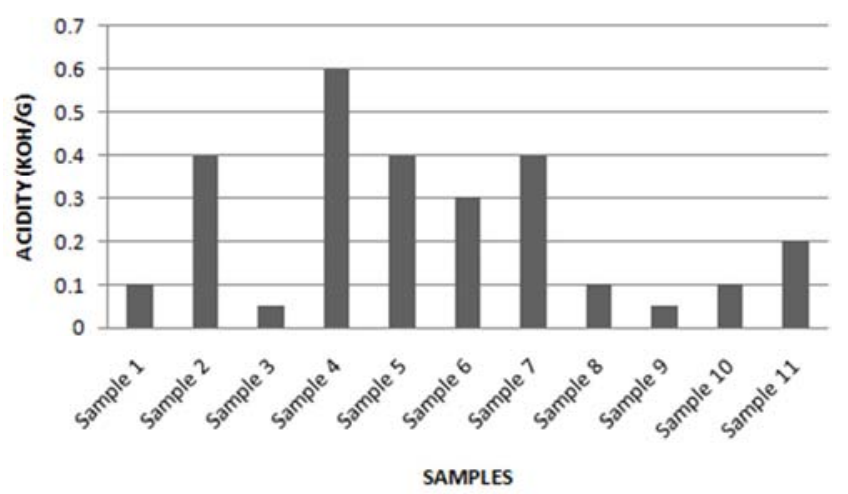

Figure 22. Comparison of Acidity values of samples using neem oil.

Figure 22 shows the comparison graph of Acidity for different samples using mahua oil.

From the Investigations of the Acidity values of the mahua oil sample the following inference were made:

1. The acidity of the oil sample gets reduced from $0.6 \mathrm{KoH} / \mathrm{g}$ to $0.05 \mathrm{KoH} / \mathrm{g}$.

2. The acidity value for Sample 3 and 9 that is when selenium and when beta carotene, selenium and TBHQ is added is low.

\subsection{Comparison of the Blending of Three Oils with Regenerative Materials}

The evaluation of critical parameters of the three oils by way of different proportions through the addition of regenerative materials like TBHQ, Selenium, Beta Carotene, Aluminium Nitride and Carbon Nanopowder were made are discussed below.

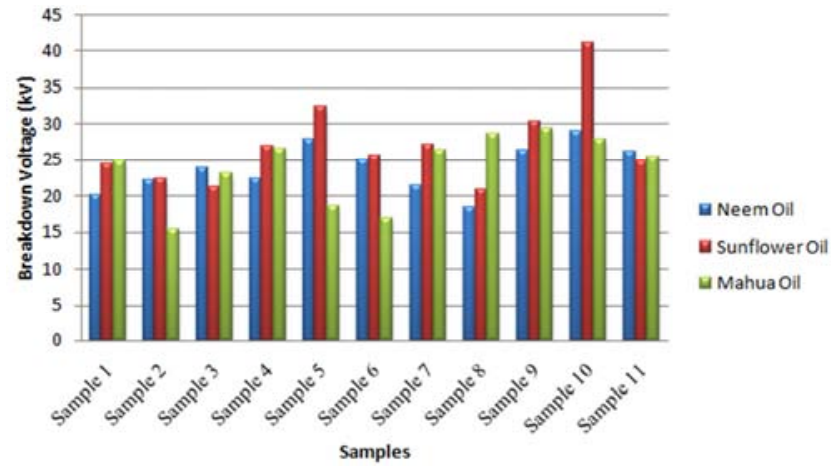

Figure 23. Comparison of Breakdown Voltage values of samples using three oils.

Figure 23 shows the comparison graph of breakdown voltage for different samples using three oils. 
From the Investigations of the breakdown Voltage of the three oil sample the following inference were made:

1. Breakdown Voltage of the sunflower oil when mixed with carbon nano powder is high.

2. For all the oils the breakdown voltage is higher when antioxidants and nano powder is added.

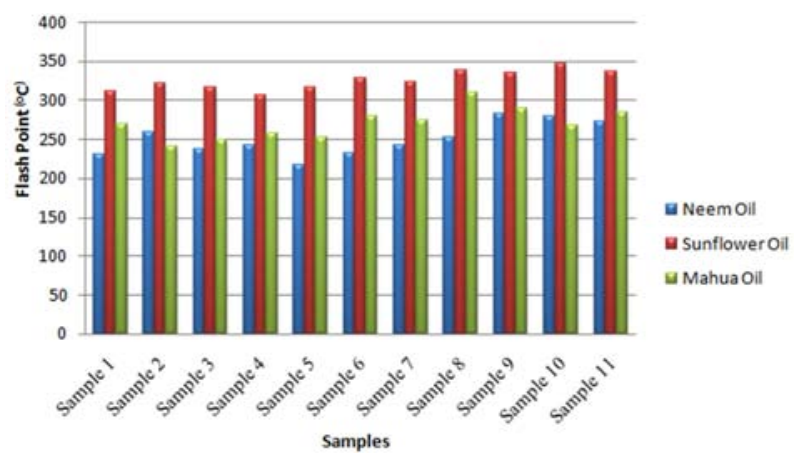

Figure 24. Comparison of Flash Point values of samples using three oils.

Figure 24 shows the comparison graph of Flash Point for different samples using three oils.

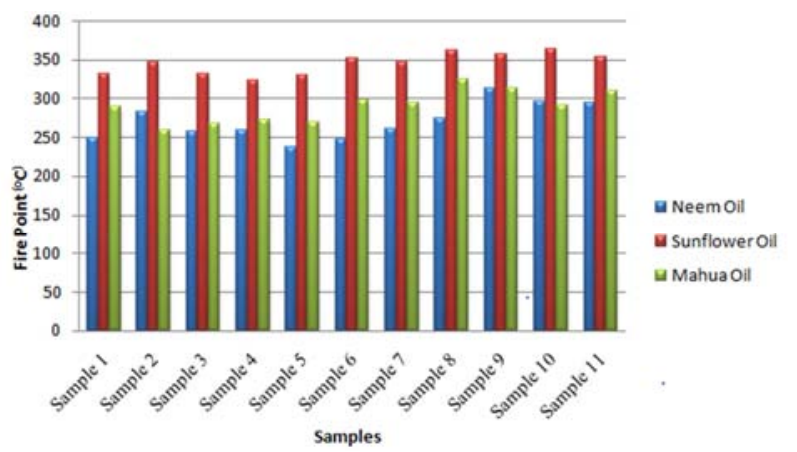

Figure 25. Comparison of Fire Point values of samples using three oils.

Figure 25 shows the comparison graph of Fire Point for different samples using three oils.

From the Investigations of the Flash Point and Fire Point of the three oil sample the following inference were made:

1. The flash point is high in sample 10 when sunflower oil is added.

2. The fire point is high in sample 10 when sunflower oil is added.

3. The flash point and Fire point for the entire sample increases when antioxidants and nano powder is added.

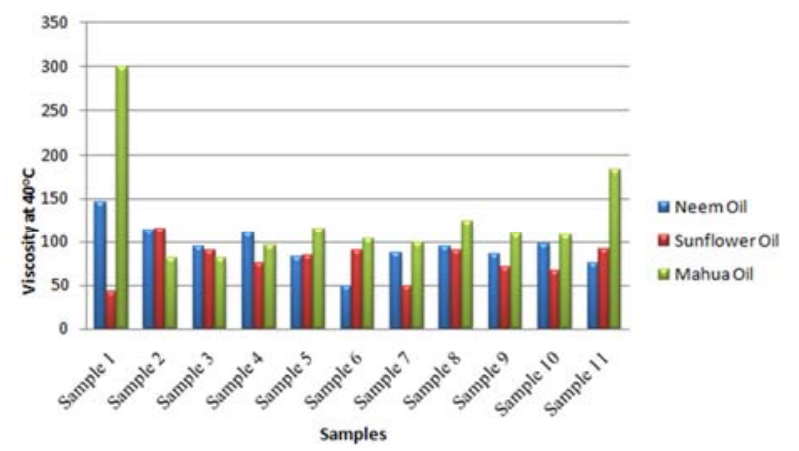

Figure 26. Comparison of Viscosity values of samples using three oils at $40^{\circ} \mathrm{C}$.
Figure 26 shows the comparison graph of Viscosity at for different samples using three oils at $40^{\circ} \mathrm{C}$.

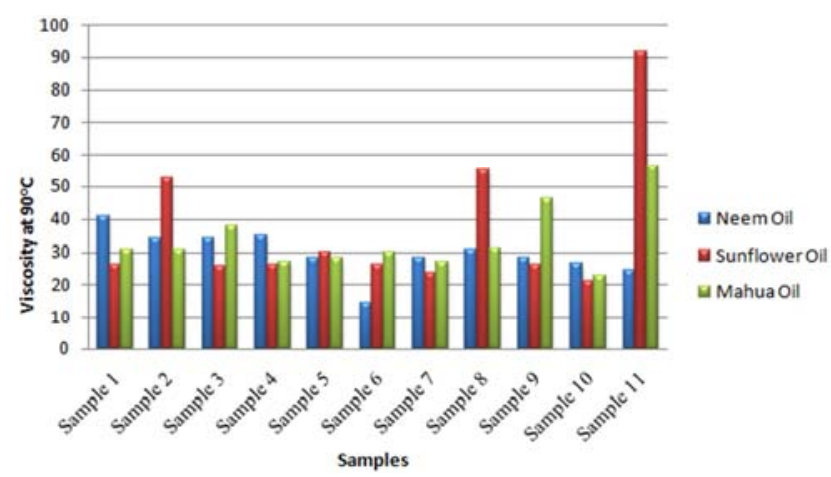

Figure 27. Comparison of Viscosity values of samples using three oils at $90^{\circ} \mathrm{C}$.

Figure 27 shows the comparison graph of Viscosity for different samples using three oils at $90^{\circ} \mathrm{C}$.

From the Investigations of the Viscosity values of the three oil sample the following inference were made:

1. At $40^{\circ} \mathrm{C}$, the sample 10 when carbon nano powder is added the viscosity value reduces.

2. At $90^{\circ} \mathrm{C}$, the sample 10 when carbon nano powder is added the viscosity value reduces.

3. Usually lower the viscosity value gives the better oil sample.

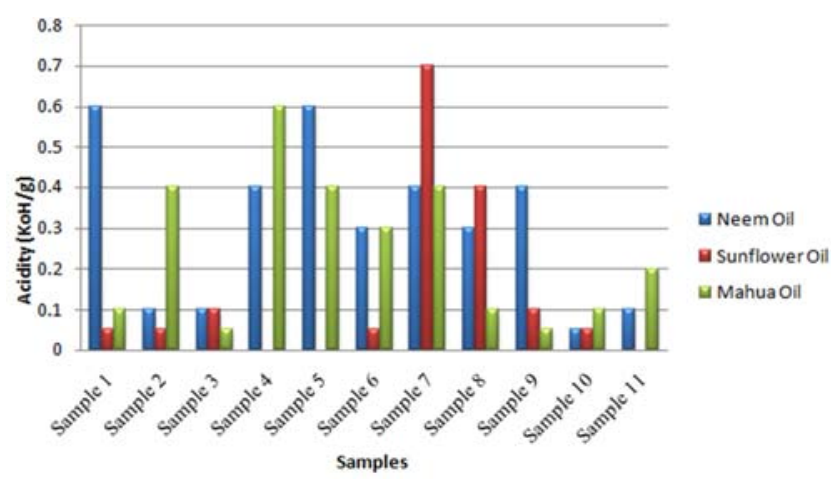

Figure 28. Comparison of Viscosity at Acidity values of samples using three oils.

Figure 28 shows the comparison graph of Acidity values for different samples using three oils.

From the Investigations of the Acidity values of the three oil sample the following inference were made:

1. The acidity of the oil sample of 4,5 and 11 is very low for sunflower oil.

2. Usually sunflower oil has lower acidity value.

\section{Conclusion}

Transformers are the most important component in the electrical power system. The analysis is used to establish the reclamation of vegetable oil. Moreover, the combination of antioxidants (TBHQ, Selenium and Beta Carotene) and Nano Powders (Aluminium Nitride and Carbon Nano Powder) is a proven technique for enhancing the properties of vegetable 
oil. The important features of using antioxidants and nanopowders combination during experimentation apart from enhancement property are very less carbon content during the breakdown. After the addition of regenerative materials, the parameters such as BDV, Viscosity, Flash point and Fire point gets increased. This approach is also useful in avoiding harmful disposal of used transformer oil to the environment. The overall investigation concludes that the enhanced oils using regenerative materials, nanopowders and antioxidant is an appropriate solution for potential reuse in power transformer.

\section{References}

[1] IEEE. Guide for Loading Mineral Oil Immersed Transformer, AnnexI: Transformer Insulation Life, IEEE Standard C57.91, 1995.

[2] Vishal, Saurabh, Vikas and Prashant, "Transformer's History and itsInsulating Oil", 5th National Conf., INDIACom, Computing for Nation Development, 2011.

[3] K. Sindhuja, M. Srinivasan and N. Niveditha, "Natural Esters as an alternative to Mineral Oil in Transformer Applications," InternationalJournal of Pure and Applied Mathematics, vol. 118 No.20, pp. 723-732, 2018.

[4] Pavel Totzauer, Pavel Trnka, Jaroslav Hornak, Petr Kadlec, Josef Pihera, "Antioxidant variation in the ester oil," IEEE Conference, 2017.

[5] M. Thanga Rathna, R. V. Maheswari, P. Samuvel Pakkianathan, "Enhancing the properties of used mineral oil by Regeneration process," IEEE Conference, 2017.

[6] 'M. Karthik, M. Willjuice Iruthayarajan and M. Bakrutheen, "Investigation of Vegetable oil blended with Antioxidant," IEEE conference, 2015'.

[7] 'Arun Ram Prasath. R. T, Willjuice Iruthayarajan. M. S, Radha. K, "Performance studies on dielectric and physical properties of eco - friendly based natural ester oils using semiconductive nanocomposites for power transformer application," Institution of Engineering and Journals, 2017'.

[8] Senthil Kumar. S, Willjuice Iruthayarajan. M, Bakrutheen. M, "Effect of Antioxidants on critical Properties of Natural Esters for Liquid Insulations," IEEE Transactions on Dielectric and Electrical Insulation, 2016.

[9] Pavel Totzauer, Pavel Trnka, Vaclav Mentlik, Jaroslav Hornak, PetrKadlec, Jiri Ulrych, Josef Pihera, "A study of various inhibitors mixtures in Natural ester oil," IEEE conference, 2017.

[10] 'Raymon. A, Karthik. R, "Reclaiming Aged Transformer Oil with Activated Bentonite and Enhancing Reclaimed and Fresh Transformerr Oils with Antioxidants," IEEE Transactions on Dielectric and Electrical Insulation, 2015'.

[11] Raymon. A, Samuel Pakianathan. P, Rajamani. M. P. E, Karthik. R, "Enhancing the Critical Characteristics of Natural Esters with Antioxidants for Power Transformer Applications," IEEE Transactions on Dielectric and Electrical Insulation, 2013.

[12] Krishna Kumar. P, Senthil Kumar. S, Ravindran. M, "Investigationon Mixed Insulating Fluids with Nano Fluids and Antioxidants", IEEE Conference 2014.

[13] Samuel Pakianathan. P, Rajamani. M. P. E, "Enhancing the Critical Characteristics of Vegetable Oil and used Mineral Oil of Power Transformer," IEEE Conference, 2013.

[14] R. Madhavan, S. Senthil Kumar, M. Willjuice Iruthayarajan, "A Comparative investigation on the effects of nanoparticles on characteristics of natural ester based nano fluids," Elsevier Journal, Colloids and Surfaces A 556, 2018.

[15] S. Senthil Kumar, M. Willjuice Iruthayarajan, M. Bakrutheen, "Investigation on the suitability of Rice Bran Oil and Corn Oil as Alternative Insulating Fluids for Transformer," IEEJ Transactions on Electrical and Electronic Engineering, 2016.

[16] S. Senthil Kumar, M. Willjuice Iruthayarajan, M. Bakrutheen, "Performance Of Activated Bentonite And Carbon In Reclaiming The Properties Of Used Mineral Oil," Journal of Electrical Engineering, 2017.

[17] P. Joeljoshuva, A. Prabhu, R. Arun Kumar, S. Senthil Kumar, "Investigation of various Natural Esters Insulating Medium for the Applications in High Voltage Machinery," International Journal of Advanced Research in Basic Engineering Sciences and Technology, 2018.

[18] R. Karthik, T. S. R. Raja, S. S. Shanmugam and T. Sudhakar, Performance Evaluation of Ester oil and Mixed Insulating Fluids, J. Institute of Eng., India, Series B, Springer, Vol. 93, No. 3, pp.173-178, 2012.

[19] R. Karthik and SreeRenga Raja. T, "Investigations of Transformer Oil Characteristics", IEEJ-Trans. Electr. Electronics Eng., Vol. 7, pp. 369-374, 2012.

[20] M. Bakrutheen, R. Karthik and R. Madavan, "Investigation of Critical Parameters of Insulating Mineral Oil Using Semiconductive Nanoparticles", IEEE Int'l. Conf. Circuits, Power and Computing Technologies - ICCPCT, pp. 294-299, 2013.

[21] ASTM D 93. Standard Test Methods for Flash Point by Pensky-Martens Closed Cup Tester, 2012.

[22] ASTM D 3828. Standard Test Method for Kinematic Viscosity of Transparent and Opaque Liquids (and the Calculation of Dynamic Viscosity), Annual book of ASTM standard 10.03, 2006. 